\title{
From the Desk of the Executive Editor
}

(BIRDEM Med J 2020; 10(3): 222)

This peer reviewed journal is an important assortment of different articles related to various disciplines of medical and allied sciences. It welcomes original articles, review articles, meta-analysis, systematic reviews and case reports. It expects and appreciates the contribution of Physicians and allied professionals of different medical/scientific institutions from home and abroad. Anyone can go through the articles by browsing www.birdemmedj.org - our website. Our ISSN is (print 2305-3712, online 2305-3720). We are registered to Bangladesh Medical and Dental Council (BMDC) and enrolled to BanglaJOL. Authors can submit manuscript on line. The statistics of our online viewer is enthusiastic and very much encouraging.

In this issue we have to increase the number of original articles as we have available good manuscripts due to encouraging response from readers and authors. This proves endorsement of quality, peer reviewing and needless to say the timely publication of the journal. In this issue we have highlighted controversies of corona as editorial. Corona, COVID-19 has jolted medical science and threatened health facilities all over. We need to enrich our knowledge and research to overcome corona threat.

We feel tremendously buoyed by our readers' participation and their responses from all over the globe. We are very much thankful to our online readers. We also express our pristine appreciation and gratefulness to the authors who bolster our hope immensely and enrich the journal aptly with valuable articles. The editorial board and advisory board are eagerly looking forward to your valuable criticism, advices and recommendation to improve our endeavor.

Eagerly waiting for your new articles.

Prof. Khwaja Nazim Uddin

Executive editor

BIRDEM Medical Journal 